\title{
Imploding Water Wave: a Poppy Blossom
}

\author{
Anna Chtchetinina and Hoi Dick $\mathrm{Ng}^{\dagger}$ \\ Department of Mechanical and Industrial Engineering, Concordia University, \\ Montréal, Québec, H3G 1M8, Canada
}

\author{
${ }^{\dagger}$ Corresponding Author \\ Department of Mechanical and Industrial Engineering \\ Concordia University \\ 1455 de Maisonneuve Blvd. West \\ Montréal, H3G 1M8, Canada \\ e-mail: hoing@encs.concordia.ca \\ Tel.: (514) 848-2424 (ext. 3177) \\ Fax: (514) 848-3175
}

Winning entry submitted to

Gallery of Fluid Motion, Physics of Fluids

July, 2012 


\section{Imploding Water Wave: a Poppy Blossom}

\section{Submitted by}

\section{Anna Chtchetinina and Hoi Dick Ng, Concordia University, Montréal, QC, Canada}

Implosion of surface waves is ubiquitous in nature, and provides an important analogy for many physical phenomena. For example, when a heavy solid object (such as a meteoroid) impacts a fluid surface (such as the planet's ocean), a crater is created and subsequently begins to pinch radially inward, resulting in the formation of a vertical water jet. ${ }^{1}$ In the shallow water limit, surface wave implosion also has an analogue in nuclear energy fusion, where gasdynamic shock waves are imploded to generate dense plasmas of extremely high temperature at the center. ${ }^{2}$ In this study, the dynamics of an imploding circular water wave are simulated experimentally using a simple gate-type water table $(90 \times 105 \times 20 \mathrm{~cm})$ and high-speed video imaging. ${ }^{3,4}$ A circular, converging water wave is created by rapidly retracting a gate separating a region of high water level from a region with lower water level. Four cylindrical obstacles are placed in the path of the collapsing wave to test the stability of the imploding wave.

Figure 1 shows a sample snapshot of this implosion process just before the wave breaks at the center, visualized from the bottom of the water table. For a better quality of representation, the raw image is enhanced by the ImageJ software. ${ }^{5}$ From the picture, the center of convergence of the water wave coincides with the center of symmetry of the implosion. The transient, inwardsweeping turbulent flow created by the retracting gate, as well as the outward-sweeping trajectory of the disturbances on the water wave caused by the four cylindrical obstacles, can be seen and traced. A sequence of images of this implosion process until the water wave breaks at the center, visualized from the bottom of the water table, is also given in Fig. 2. 
Artistically, the implosion core resembles the shape of a remembrance poppy. In Canada, as in many other countries, the red poppy flower is the symbol of remembrance worn on the left lapel during the two weeks before the Remembrance Day on November 11 to commemorate members of the armed forces who died during war in the service of their country. ${ }^{6}$

\section{Acknowledgement}

The authors are grateful to A.J. Higgins and C.B. Kiyanda for their valuable help to this project. This research is supported by the Natural Sciences and Engineering Research Council of Canada (NSERC).

\section{References}

${ }^{1}$ S. Gekle, J.M. Gordillo, D. Van der Meer, D. Lohse, "High-speed jet formation after solid object impact,” Phys. Rev. Lett. 102, 034502 (2009)

${ }^{2}$ R.W. Perry, A. Kantrowitz, “The production and stability of converging shock waves,” J. Appl. Phys. 22, 878-886 (1951)

${ }^{3}$ C.B. Kiyanda, P. Chaput, A.J. Higgins, J.H.S. Lee "Investigation of imploding shock waves using hydraulic analogy,” Proc. 24th Int. Symp. on Shock Waves, 745-750 (2004).

${ }^{4}$ A.L. Gunter, O. Smadi, L. Kadem, H.D. Ng, "Visualization of an imploding circular hydraulic jump and the formation of a central vertical jet,” J. Visualization 14, 19-22 (2011)

${ }^{5}$ W.S. Rasband, “Image J,” U.S. National Institutes of Health, Bethesda, Maryland, USA, http://rsb.info.nih.gov/ij/, 1997-2009.

${ }^{6}$ Veterans Affairs Canada - http://www.veterans.gc.ca/eng/remembrance 


\section{Figure Caption}

FIG. 1. Snapshot of an imploding circular water wave with four cylindrical obstacles in its path.

FIG. 2. A sequence of images showing the implosion of the surface water wave. 


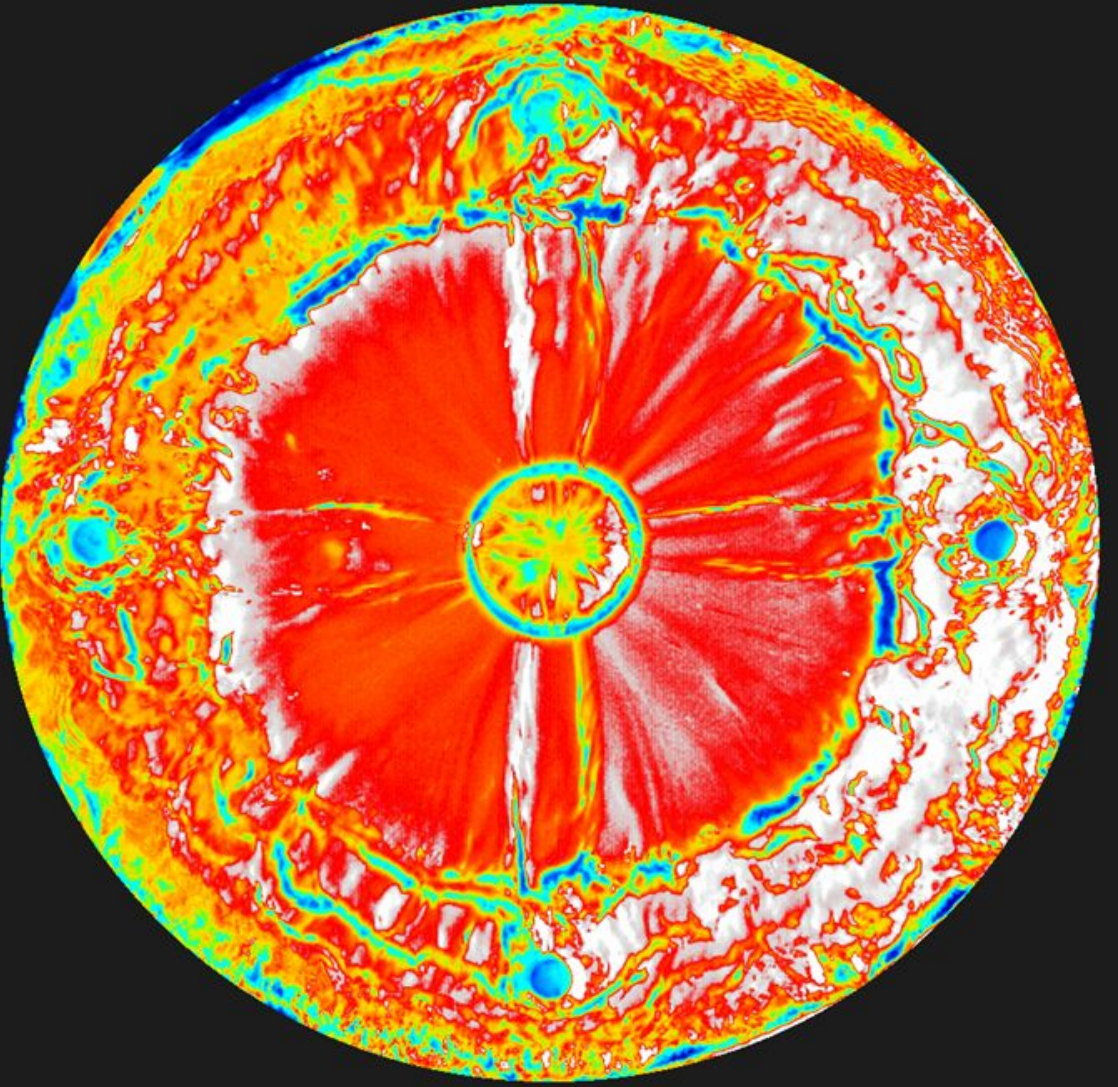




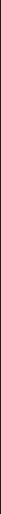




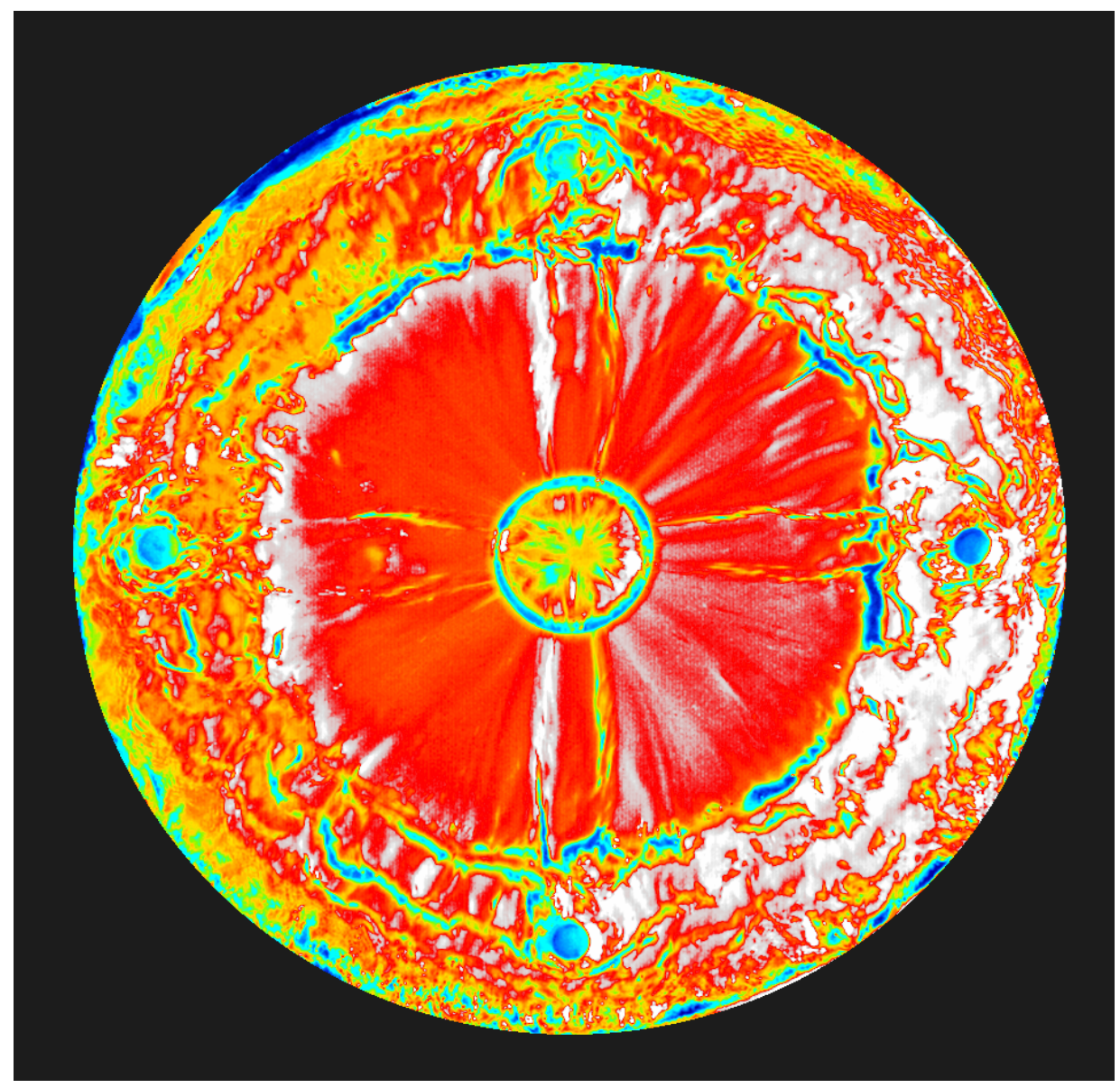




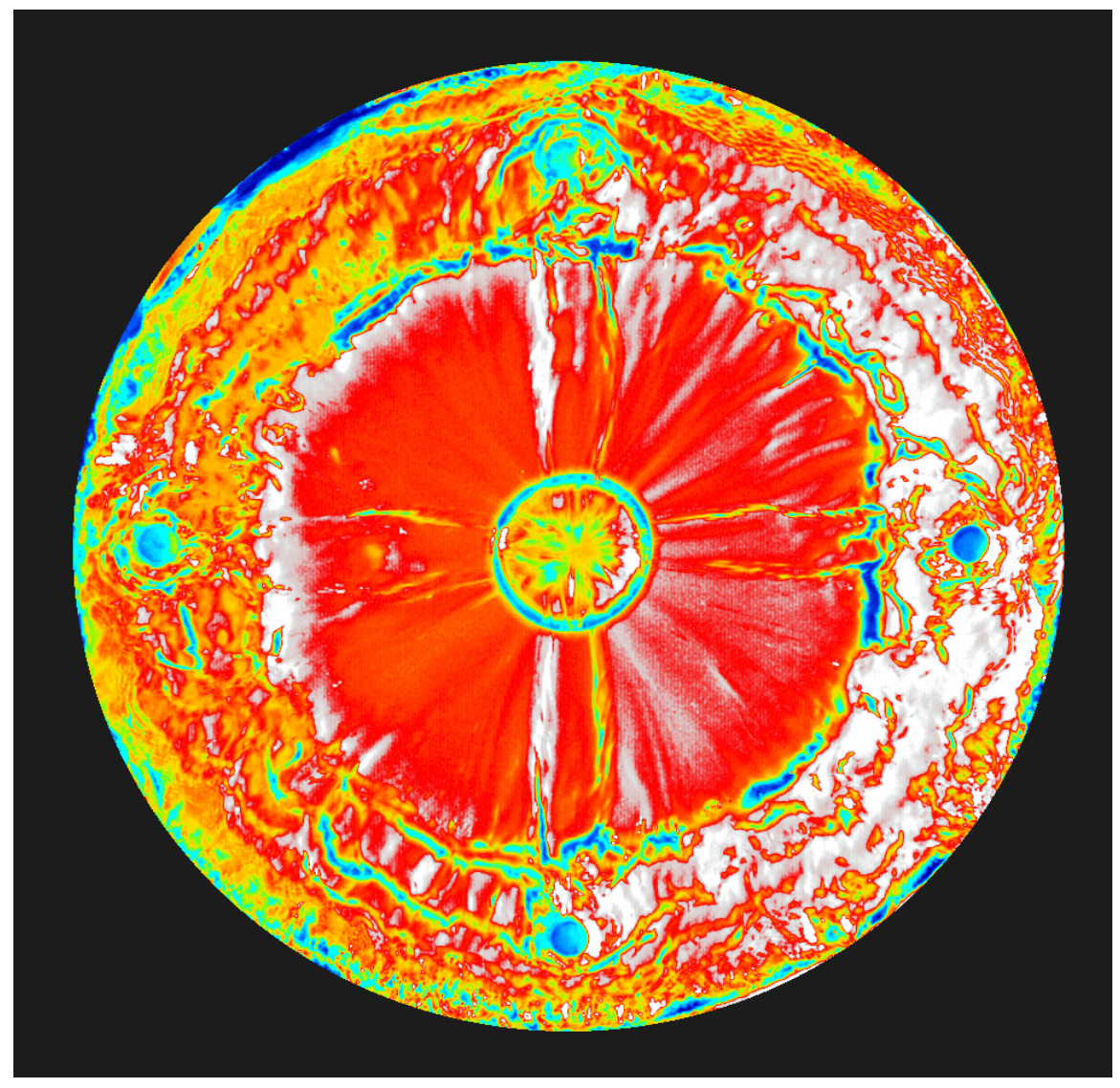




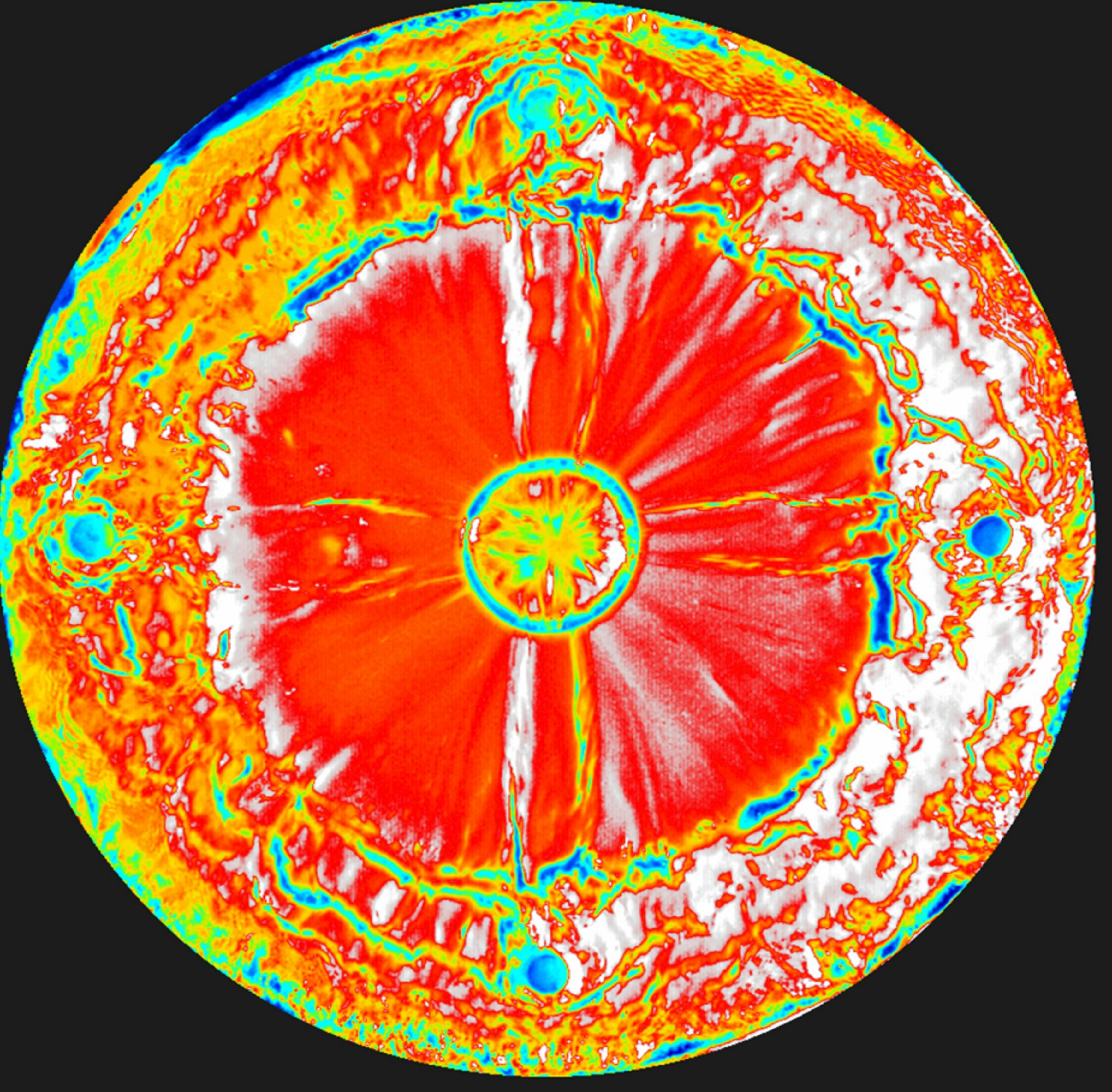




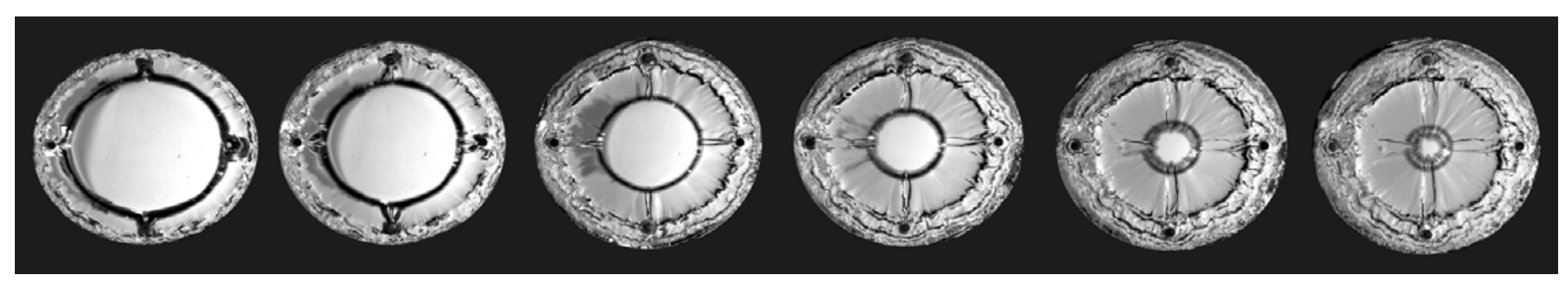




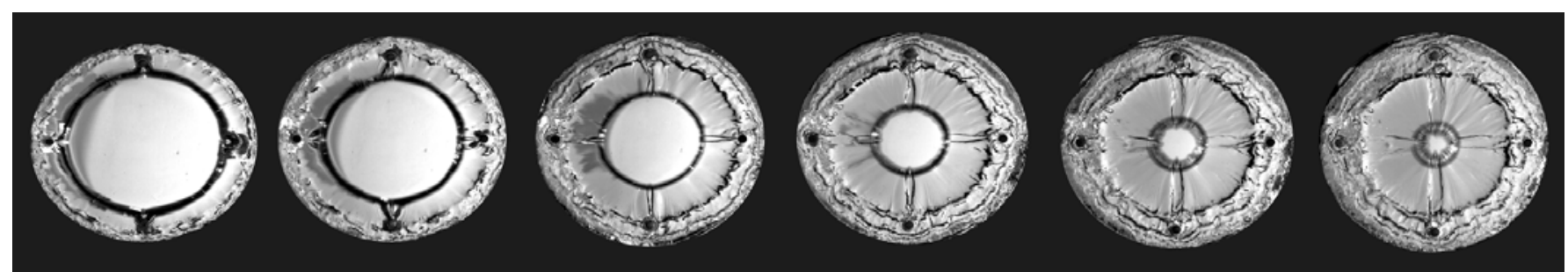

